\title{
A Model for Predicting Dynamic Cutting Forces in Sand Mould Milling with Orthogonal Cutting
}

Zhong-De Shan ${ }^{1 *}$ and Fu-Xian Zhu' ${ }^{1,2}$ (1)

\begin{abstract}
Cutting force is one of the research hotspots in direct sand mould milling because the cutting force directly affects the machining quality and tool wear. Unlike metals, sand mould is a heterogeneous discrete deposition material. There is still a lack of theoretical research on the cutting force. In order to realize the prediction and control of the cutting force in the sand mould milling process, an analytical model of cutting force is proposed based on the unequal division shear zone model of orthogonal cutting. The deformation velocity relations of the chip within the orthogonal cutting shear zone are analyzed first. According to the flow behavior of granular, the unequal division shear zone model of sand mould is presented, in which the governing equations of shear strain rate, strain and velocity are established. The constitutive relationship of quasi-solid-liquid transition is introduced to build the 2D constitutive equation and deduce the cutting stress in the mould shear zone. According to the cutting geometric relations of up milling with straight cutting edge and the transformation relationship between cutting stress and cutting force, the dynamic cutting forces are predicted for different milling conditions. Compared with the experimental results, the predicted results show good agreement, indicating that the predictive model of cutting force in milling sand mould is validated. Therefore, the proposed model can provide the theoretical guidance for cutting force control in high efficiency milling sand mould.
\end{abstract}

Keywords: Green manufacture, Cutting force, Sand mould milling, Orthogonal cutting, Quasi-solid-liquid transition

\section{Introduction}

Sand mould milling is the process of milling casting mould directly with $\mathrm{CNC}$ milling technology, in which the mould production does not use molds or patterns. Compared with the traditional casting process, a sand mould produced by milling can avoid wooden pattern making, eliminate the work steps of the casting process and reduce energy consumption [1]. So, the sand mould milling process is a typical example of green manufacturing, and is considered as a revolution in the field of traditional casting in single and mini-batch casting production. An accurate prediction of the dynamic cutting forces of milling sand mould is very important to study

\footnotetext{
*Correspondence: shanzd@cam.com.cn

${ }^{1}$ State Key Laboratory of Advanced Forming Technology and Equipment, China Academy of Machinery Science Technology, Beijing 100083, China Full list of author information is available at the end of the article
}

the ability of the process, surface quality, and monitoring the tool wear [2].

Milling is one of the most complex machining processes. At present, the models for predicting cutting forces mainly include empirical model, numerical model, artificial intelligence model and analytical model. The empirical model is expressed as an exponential function of cutting force and process parameters, based on the statistical and regression analysis of orthogonal experimental results [3]. FEM is the common numerical method for building the model, which can be used to analyze the chip deformation, tool wear, stress and temperature distribution, and optimize the process parameters. Through artificial neural network (ANN) [4] and particle swarm optimization (PSO) and other modern artificial intelligence algorithms, more accurate milling force model is established. The 
analytical model of milling force is established by the flow stress, constitutive equation of material and geometric relations of milling, which is the combination of theory such as thermo-elastic-plastic, tribology, materials science and dynamics [5-8].

The analytical model is mainly used to predict the force of metal-cutting, for their deformation rules are analyzed clearly. In metal-cutting, the analytical model of cutting force is built based on the assumption of shear area. Merchant [9] proposed the single shear area model based on the flow rules of metal material in cutting. Oxley [5] modified the single shear area to a shear zone and established the parallel-sided shear zone model. Astakhov et al. [10], Bai et al. [7], Zhou et al. [11] divided the shear zone into two regions, i.e., wide zone and narrow zone, and predicted the cutting force by analyzing the flow rules and thermodynamics equations of material in the shear zone.

The sand mould for casting is a solidified mixture composed of original sand and binder, which can be considered as a discrete granular accumulating material with a skeletal system [2]. The deformation and flow rules of sand mould differ from those of continuum material. For granular materials, Masanobu et al. [12] and Gao et al. [13] studied the stress and strain of shear band based on both the simulation and the laboratory tests, Wang et al. [14] and, Campbell [15] studied the transition from quasi-static to inertial flow and proposed the constitutive equation of quasi-solid-liquid transition. In addition, Discrete Element Method (DEM) as an effective numerical method was used to study the force and deformation of granular system [16-18]. Jerzy [19] set up the thermal-mechanical coupling model of rock cutting based on DEM and simulated the process and dynamic cutting force. Nevertheless, there is a large number of computation, and the deformation and cutting mechanism of rock cutting were not studied, and the prediction model of cutting force was not presented.

Sand mould milling is a new process for sand mould production, no in-depth study has yet been made for the cutting mechanism of sand mould. There is limited literature on the study of sand mould cutting force. The quasi-solid-liquid transition feature of granular materials can be considered as an appropriate basis for further studying the deformation of shear area when cutting sand mould. In order to improve the integrity and accuracy of sand mould structure and reduce the tool wear by controlling the size of cutting force, in this paper, the quasi-solid-liquid transition theory of granular system is introduced into the parallel-sided shear zone model of the cutting process to analyze the flow stress of shear zone. Through studying the shear strain rate of shear zone, the model of dynamic cutting forces in sand mould milling is established. Then, the cutting force of milling with straight cutting edges is predicted and discussed.

\section{Theoretical Analysis and Modeling}

\subsection{Cutting Velocity Analysis of Sand Mould}

The sand mould is a piled mixture composed of silica sand and binder. The enlarged view of the surface of sand mould is shown in Figure 1a. The strength and stiffness of sand are significantly higher than the curable binder, which means that the movement and separation of the chip are due to the deformation and fracture of the binding bridge among the sand particles [2]. The sand particles in the chip only move rigidly. The chip is presented by many disconnected sand particles each other as shown in Figure 1b. On macro-scale, the shear feature in cutting sand mould is similar to that of cutting metal, so it must obey some rules of continuum mechanics such as the chip's moving velocity. In the deformation analysis of metal-cutting, Oxley [5] proposed the parallel-sided shear zone model, which was divided into the wide zone and narrow zone by Astakhov et al. [10], as shown in Figure 2 . The cutting velocity changes slowly in the wide zone, while it changes quickly in the narrow zone. The shear strain rate in the shear zone follows the nonlinear relationship with the position as discussed in Ref. [10].

In Figure 2, $a$ is the thickness of cutting layer, $v$ is the cutting velocity, $\gamma_{0}$ is the rake angle, $\phi$ is the shear angle, $v_{\mathrm{T} 0}$ and $v_{\mathrm{n} 0}$ are the tangential and normal velocity of chip on

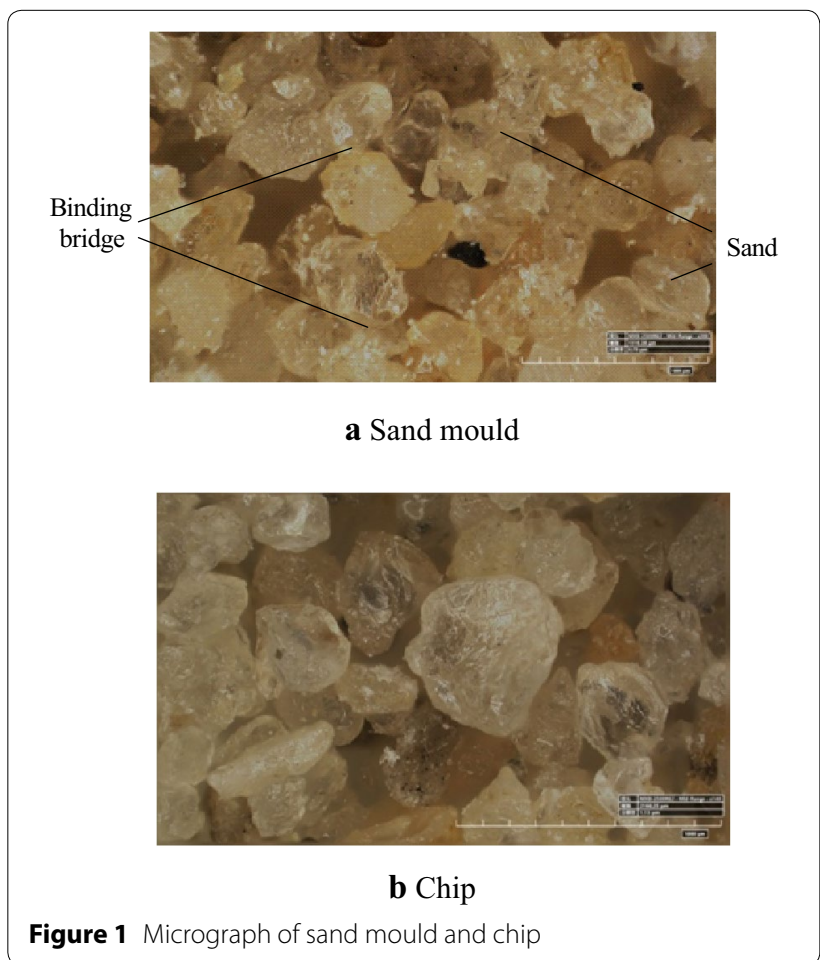




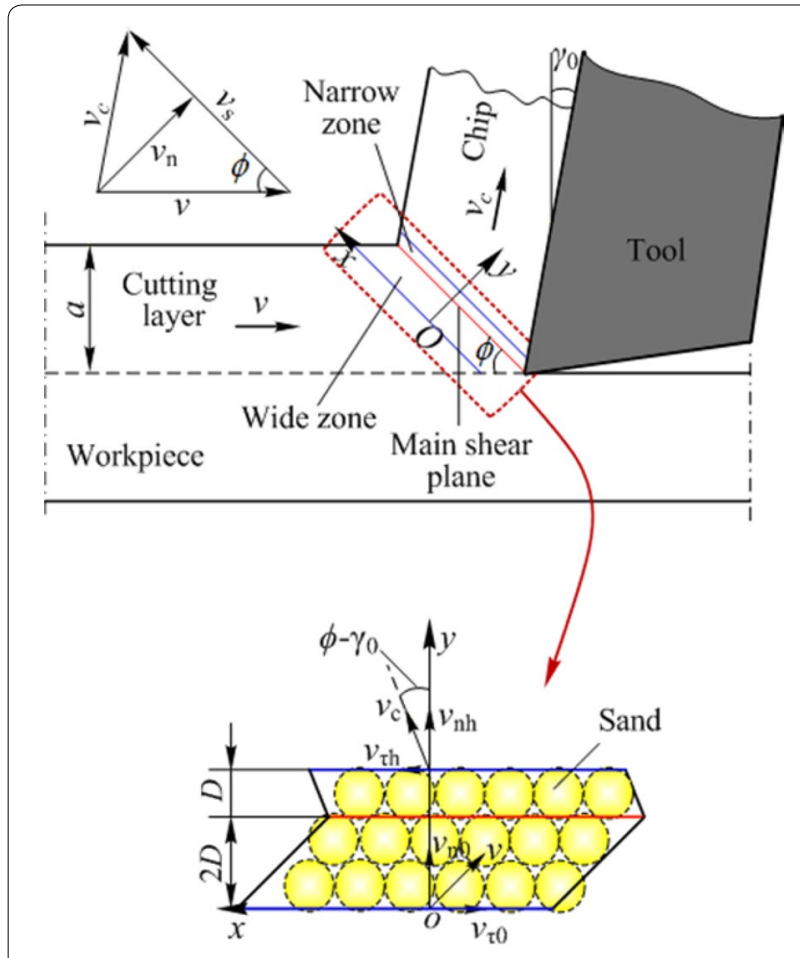

Figure 2 Unequal division shear zone model of sand mould

the initial boundary of shear zone respectively, $v_{\mathrm{th}}$ and $v_{\mathrm{nh}}$ are the tangential and normal velocity of chip on the terminal edge of shear zone respectively. Assume that the volume remains constant during cutting by ignoring the dilatancy effect of granular system. According to the continuity conditions of chip flow, the velocity in the shear zone can be written as

$$
\frac{\partial v_{x}}{\partial x}+\frac{\partial v_{y}}{\partial y}=0
$$

In the cutting space, the shear zone can be seen as onedimensional model discussed in Refs. $[9,10]$, so the variables of shear zone such as the velocity, stress, strain, and strain rate are only the functions of $y$ coordinate. According to Eq. (1), $v_{y}$ within the shear zone can be considered constant.

Figure 2 shows the relation of cutting velocities within the shear zone, from which the relation is given as follows:

$$
\begin{aligned}
& v_{x}(0)=v_{\tau 0}=-v \cos \phi, \\
& v_{x}(h)=v_{\tau h}=v \sin \phi \tan \left(\phi-\gamma_{0}\right), \\
& v_{y}(0)=v_{\mathrm{n} 0}=v \sin \phi, \\
& v_{y}(h)=v_{\mathrm{nh}}=v_{\mathrm{c}} \cos \left(\phi-\gamma_{0}\right),
\end{aligned}
$$

$$
\begin{aligned}
& v_{\mathrm{s}}=v \frac{\cos \gamma_{0}}{\cos \left(\phi-\gamma_{0}\right)}, \\
& v_{\mathrm{c}}=v \frac{\sin \phi}{\cos \left(\phi-\gamma_{0}\right)},
\end{aligned}
$$

where $v_{\mathrm{s}}$ and $v_{\mathrm{c}}$ are the tangential velocity and flow velocity of chip respectively.

\subsection{Deformation Analysis of Cutting Sand Mould}

In the analytical model of cutting force, the thickness of shear zone is the key to study the deformation of cutting. For metal-cutting, the thickness of shear zone affects the shear strain rate $\dot{\gamma}[20]$. By the analysis of quick stop micrograph from cutting experiments in Ref. [20], the thickness is regarded as half of the cutting layer thickness. In the sand mould milling process, the cutting layer thickness is changed to a sinusoid (Sect. 2.4), and the cutting layer thickness varies from 0 to $1.4 \mathrm{~mm}$ per cutting tooth. According to the thickness of shear zone in the metal cutting, the average thickness of shear zone can be approximated by $0.4 \mathrm{~mm}$, meaning the thickness of shear zone is just the thickness of 3 piled sand granules with the average mesh granularity of 100 . For the granular system, Oda et al. [12] suggested that the shear zone width of the granular system without binding is about 7-8 granules, which was also reported by Vardoulakis [21]. Moreover, Oda et al. [12] pointed out that the thickness reduces if there is the rotational resistance at contacts according to the comparison between the simulation and laboratory tests. To the sand mould, there are some binding bridges among the sands, so its shear zone thickness must be smaller than that of the granular system without binding. Considering both the aspects of shear zone thickness in metal cutting and the bound granular system, the assumption that the shear zone thickness of sand mould cutting is $3 D$ can be made, in which the thickness of wide zone is $2 D$, that of narrow zone is $D$, as shown in Figure 2 .

Because of the deformation relation of continuum mechanics in a macro-scale, the shear strain rate of shear zone can be written as

$$
\dot{\gamma}=\frac{\partial v_{x}}{\partial y}+\frac{\partial v_{y}}{\partial x}=\frac{\mathrm{d} v_{x}}{\mathrm{~d} y} .
$$

On the other hand, the shear strain rate $\dot{\gamma}$ is also the material derivative of shear strain $\gamma$

$$
\dot{\gamma}=\frac{\mathrm{d} \gamma}{\mathrm{d} t}=\frac{\partial \gamma}{\partial t}+\frac{\partial \gamma}{\partial y} \frac{\partial y}{\partial t}=v_{\mathrm{n}} \frac{\partial \gamma}{\partial y}=v \sin \phi \frac{\mathrm{d} \gamma}{\mathrm{d} y} .
$$

During the cutting process, the sands maintain rigid and move rigidly, therefore, the shear strain rate of the sand in the same layer (one sand granule's thickness) 
can be considered as unchanged. So, the shear strain rate in shear zone can be defined as a piecewise constant function

$$
\dot{\gamma}= \begin{cases}a_{1}, & y \in[0, D] \\ a_{2}, & y \in[D, 2 D] \\ a_{3}, & y \in[2 D, 3 D] .\end{cases}
$$

According to Refs. [5] and [10], $a_{1}, a_{2}$, and $a_{3}$ in Eq. (10) can be defined as a power function of sand position

$$
\left\{\begin{array}{l}
a_{1}=\frac{\dot{\gamma}_{\mathrm{m}}}{(2 D)^{q}}\left(\frac{D}{2}\right)^{q}, \\
a_{2}=\frac{\dot{\gamma}_{\mathrm{m}}}{(2 D)^{q}}\left(\frac{3 D}{2}\right)^{q}, \\
a_{3}=\frac{\dot{\gamma}_{\mathrm{m}}}{D^{q}}\left(\frac{D}{2}\right)^{q},
\end{array}\right.
$$

where $D=\sqrt{3} d / 2, d$ is the diameter of sand particle, $\dot{\gamma}_{\mathrm{m}}$ is the maximum shear strain rate within shear zone. Figure 3 shows the distribution of shear strain rate in the shear zone.

Within the shear zone, shear strain $\gamma$ can be written from Eqs. (9), (10) and (11) as

$$
\gamma(y)= \begin{cases}\frac{a_{1}}{v \sin \phi}, & y \in[0, D], \\ \frac{a_{2}}{v \sin \phi}(y-D)+\frac{\dot{\gamma}_{\mathrm{m}} D}{4^{q_{v} \sin \phi},} & y \in[D, 2 D], \\ \frac{a_{3}}{v \sin \phi}(y-2 D)+\left(\frac{1+3^{q}}{4^{q}}\right) \frac{\dot{\gamma}_{\mathrm{m}} D}{v \sin \phi}, & y \in[2 D, 3 D] .\end{cases}
$$

Within the shear zone, velocity $v_{x}$ can be written from Eqs. (8), (10) and (11) as

$$
v_{x}(y)= \begin{cases}\frac{\dot{\gamma}_{\mathrm{m}}}{4 q}-v \cos \phi, & y \in[0, D], \\ \left(\frac{3}{4}\right)^{q} \dot{\gamma}_{\mathrm{m}}(y-D)+\frac{\dot{\gamma}_{\mathrm{m}} D}{4^{q}}-v \cos \phi, & y \in[D, 2 D], \\ \frac{\gamma_{\mathrm{m}}}{2^{q}}(y-3 D)+v \sin \phi \tan \left(\phi-\gamma_{0}\right), & y \in[2 D, 3 D] .\end{cases}
$$

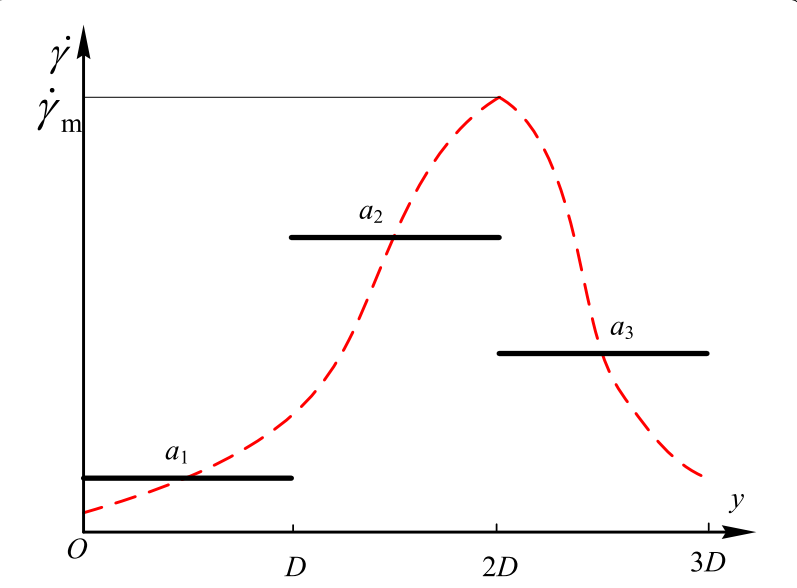

Figure 3 Distribution of shear strain rate
The cutting velocity components along shear direction ( $x$-direction) on both sides of the main shear plane change are in opposite direction as discussed in Ref. [22], so the velocity along shear direction on main shear plane may be regarded as equal to zero, that is

$$
\begin{aligned}
v_{x}(2 D) & =\left[\left(\frac{1}{4}\right)^{q}+\left(\frac{3}{4}\right)^{q}\right] \dot{\gamma}_{\mathrm{m}} D-v \cos \phi \\
& =-\left(\frac{1}{2}\right)^{q} \dot{\gamma}_{\mathrm{m}} D+v \sin \phi \tan \left(\phi-\gamma_{0}\right) \\
& =0 .
\end{aligned}
$$

From Eq. (14), the parameters $q$ and $\dot{\gamma}_{\mathrm{m}}$ can be deduced as

$$
\begin{aligned}
& \frac{\left(3^{q}+1\right)}{2^{q}}=\frac{1}{\tan \phi \tan \left(\phi-\gamma_{0}\right)}, \\
& \dot{\gamma}_{\mathrm{m}}=\frac{2^{q} v \sin \phi \tan \left(\phi-\gamma_{0}\right)}{D} .
\end{aligned}
$$

\subsection{Constitutive Equation of Cutting Sand Mould}

The physical property of sand mould can be considered as the same of continuous medium on a macro-scale. During the sand mould milling process, the rake face of milling cutter moving at high velocity squeezes the sand mould and the binding bridges among the sands in the shear zone are forced to bend and shear, causing the bonded sands to shear along the shear plane. When all the binding bridges break, the chip becomes a flowing granular system. So, the process of cutting sand mould is similar to the process of the granules transition from solid state to liquid state. In addition, the test results show that the temperature of cutter does not increase significantly during the process [2], so the effect of temperature on cutting force can be neglected.

Two types of generalized constitutive equationto describe the quasi-solid-liquid transition of granular materials exist. Campbell [15] suggested that the volume fraction, shear rate, density, size, contact stiffness, friction coefficient, and restitution coefficient of granular affect the flow characteristics of granular materials and defined the generalized constitutive equation as

$$
\sigma_{i j}=f_{i j}\left(C_{\mathrm{v}}, \dot{\gamma}, \rho_{\mathrm{p}}, d, k_{\mathrm{n}}, \mu, e\right),
$$

where $C_{\mathrm{v}}$ is the volume fraction, $\dot{\gamma}$ is the shear rate, $\rho_{\mathrm{p}}$ is the density, $d$ is the diameter, $k_{\mathrm{n}}$ is the contact stiffness, $\mu$ is the friction coefficient among granules, $e$ is the restitution coefficient. Equation (17) can be changed into two forms

$$
\left\{\begin{array}{l}
\frac{\sigma_{i j}}{\rho_{\mathrm{p}} d^{2} \dot{\gamma}^{2}}=f_{i j}\left(C_{\mathrm{v}}, \mu, e\right), \\
\frac{\sigma_{i j} d}{k_{\mathrm{n}}}=f_{i j}\left(C_{\mathrm{v}}, \mu, e\right), \quad \text { in the inertial limit, }
\end{array}\right.
$$


Campbell [15] noted that the stress is linearly related to $\dot{\gamma}^{2}$ in the inertial limit and to $k_{\mathrm{n}}$ in the elastic-quasi-static limit.

Wang et al. [14] and Zhang et al. [23] proposed that the stress in different states is related to the shear rate $\dot{\gamma}$, and the function $f_{i j}$ in Eq. (17) can be expressed as the combination of the zero-order term, monomial term and quadratic term of shear rate $\dot{\gamma}$. Wang et al. [14] proposed the following quasi-solid-liquid transition constitutive equation of granular system

$$
\begin{aligned}
\sigma_{i j}= & p_{i j} I_{i j}+\left(2 k_{\tau 1} \rho_{\mathrm{p}} d^{\frac{3}{2}} g^{\frac{1}{2}}+4 k_{\mathrm{\tau} 2} \rho_{\mathrm{p}} d^{2} \sqrt{J_{2}^{\prime}}\right) D_{i j} \\
& +\left(\frac{4 k_{\mathrm{p} 1} \rho_{\mathrm{p}} d^{\frac{3}{2}} g^{\frac{1}{2}}}{\sqrt{J_{2}^{\prime}}}+2 k_{\tau 2} \rho_{\mathrm{p}} d^{2}\right) D_{i j}^{2}
\end{aligned}
$$

where $p_{i j}$ is load; $J_{2}^{\prime}=0.5 \operatorname{tr} D_{i j}^{2}$ is the second principal invariant of deviation tensor of the deformation rate $D_{i j}$, and $D_{i j}$ is deformation rate defined as

$$
D_{i j}=\frac{1}{2}\left(\frac{\partial u_{i}}{\partial x_{j}}+\frac{\partial u_{j}}{\partial x_{i}}\right) .
$$

$I_{i j}$ is a parameter reflecting the characteristic of granular system, in which

$$
\left\{\begin{array}{l}
I_{1}=\operatorname{tr} D_{i j}, \\
I_{2}=\frac{1}{2}\left[\left(\operatorname{tr} D_{i j}\right)^{2}-\operatorname{tr} D_{i j}^{2}\right], \\
I_{3}=\operatorname{det} D_{i j},
\end{array}\right.
$$

$\rho_{\mathrm{p}}$ is the grain density; $d$ is the particle diameter; $g$ is the gravitational acceleration; $k_{\mathrm{p} 1}=\alpha_{1} C_{\mathrm{vr}}^{n_{1}}, \quad k_{\mathrm{p} 2}=\alpha_{2} C_{\mathrm{vr}}^{n_{2}}$, $k_{\tau 1}=\tan \theta_{1} k_{\mathrm{p} 1}$, and $k_{\tau 2}=\tan \theta_{2} k_{\mathrm{p} 2}$ are the stress coefficients related to relative concentration of grains, $C_{\mathrm{vr}}$ is critical volume fraction. According to Hanes and Inman's [24] experimental results through dry sand, the following coefficients have been given in Ref. [14]: $n_{1}=1, n_{2}=1$, $\alpha_{1}=0.7, \alpha_{2}=0.5, \tan \theta_{1}=0.5$, and $\tan \theta_{2}=0.6$.

Like the soil, shear failure of sand mould under quasistatic loading obeys the Mohr-Coulomb strength criterion. Under uniaxial compression, the shear strength of sand mould is

$$
\tau_{\mathrm{s}}=\sigma_{\mathrm{s}}\left(\frac{\sin 2 \theta}{2}-\sin ^{2} \theta \tan \phi_{0}\right),
$$

where $\sigma_{\mathrm{s}}$ is axial compression strength, $\phi_{0}$ is the static internal friction angle, $\theta=\pi / 4-\phi_{0} / 2=\phi$ is the angle between shear plane normal and cross section.

For the sand mould milling, the flow within the shear zone can be considered as a simple shear. So, from Eqs. (19) and (22), the stress on the main shear plane of shear zone can be written as

$$
\left\{\begin{aligned}
\tau_{\varphi}= & \sigma_{\mathrm{s}}\left(\frac{\sin 2 \varphi}{2}-\sin ^{2} \varphi \tan \varphi_{0}\right) \\
& -\left(k_{\tau 1} \rho_{\mathrm{p}} d^{\frac{3}{2}} g^{\frac{1}{2}} \dot{\gamma}+k_{\tau 2} \rho_{\mathrm{p}} d^{2} \dot{\gamma}^{2}\right) \sin 2 \varphi \\
\sigma_{\varphi}= & \sigma_{\mathrm{s}} \sin ^{2} \varphi+\left(k_{\mathrm{p} 1} \rho_{\mathrm{p}} d^{\frac{3}{2}} g^{\frac{1}{2}} \dot{\gamma}+k_{\mathrm{p} 2} \rho_{\mathrm{p}} d^{2} \dot{\gamma}^{2}\right) \\
& +\left(k_{\tau 1} \rho_{\mathrm{p}} d^{\frac{3}{2}} g^{\frac{1}{2}} \dot{\gamma}+k_{\tau 2} \rho_{\mathrm{p}} d^{2} \dot{\gamma}^{2}\right) \cos 2 \varphi
\end{aligned}\right.
$$

In Eq. (23), the zero-order term of shear rate is attributed to the static support among the sand particles, in which the deformation is the failure of binding bridges; the monomial term of shear rate is due to the relative sliding and extrusion among sands; the quadratic term is due to the collision and diffusion among sands.

\subsection{Cutting Force Calculation for Milling Sand Mould}

The milling cutter with straight cutting edges is used to mill sand mould for avoiding the sand particles flying upwards. Figure 4 shows the cutting layer sketch of up milling. The momentary cutting layer thickness of the $i$ th cutter tooth can be approximately regarded as

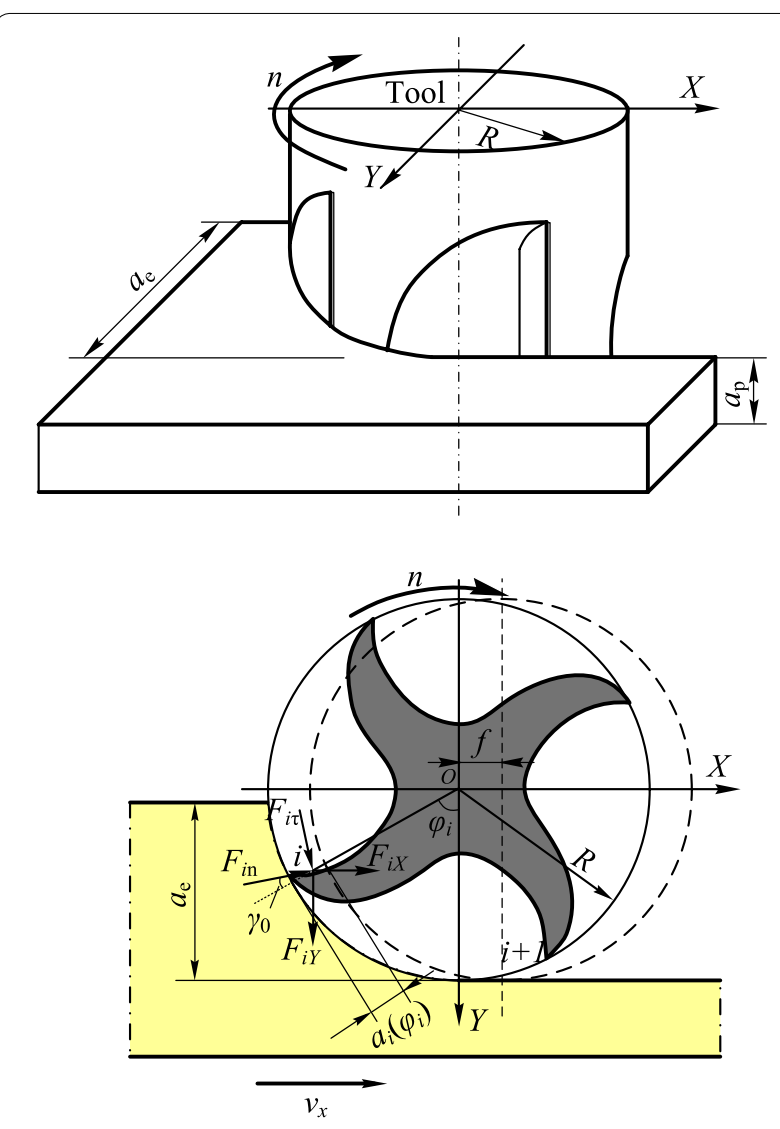

Figure 4 Cutting layer sketch of up milling 


$$
a_{i}\left(\varphi_{i}\right)=f \cdot \sin \varphi_{i}=\frac{60 \cdot v_{X}}{n Z} \sin \varphi_{i}
$$

where $f$ is the feeding per tooth, $v_{X}$ is the spindle feeding speed, $n$ is the spindle turning speed, $Z$ is the teeth number, $\varphi_{i}$ is the rotation angle of the $i$ th cutter tooth within the range $\varphi_{i} \in\left[0, \pi / 2+\arcsin \left(a_{\mathrm{e}} / R-1\right)\right]$ for up milling, in which $a_{\mathrm{e}}$ is the milling feeding and $R$ is the radius of cutter.

For the end mill without helical angle, the shear stress and normal stress on the main shear plane can be considered as uniform. So, the instantaneous cutting force on the $i$ th cutter tooth is proportional to the cutting area, and the expressions of the two components of the force are

$$
\left\{\begin{array}{l}
F_{i \tau}\left(\varphi_{i}\right)=K_{i \tau} a_{i}\left(\varphi_{i}\right) a_{\mathrm{p}} \\
F_{i \mathrm{n}}\left(\varphi_{i}\right)=K_{i \mathrm{n}} a_{i}\left(\varphi_{i}\right) a_{\mathrm{p}}
\end{array}\right.
$$

where $K_{i \mathrm{\tau}}$ and $K_{i n}$ are the tangential cutting force and normal cutting force per unit area on the $i$ th cutter tooth respectively, $a_{\mathrm{p}}$ is the spindle feeding depth.

Figure 5 shows the chip load in the steady cutting process, where

$$
\left\{\begin{array}{l}
F_{i y y}=-\sigma_{\phi} \frac{a_{i} a_{\mathrm{p}}}{\sin \phi} \\
F_{i x y}=\tau_{\phi} \frac{a_{i} a_{\mathrm{p}}}{\sin \phi}
\end{array}\right.
$$

According to the equilibrium condition of chip, the $K_{i \mathrm{\tau}}$ and $K_{i \mathrm{n}}$ can be written as

$$
\left\{\begin{array}{l}
K_{i \tau}=\sqrt{\sigma_{\phi}^{2}+\tau_{\phi}^{2}} \cdot \frac{\cos \beta}{\sin \phi} \\
K_{i \mathrm{n}}=\sqrt{\sigma_{\phi}^{2}+\tau_{\phi}^{2}} \cdot \frac{\sin \beta}{\sin \phi}
\end{array}\right.
$$

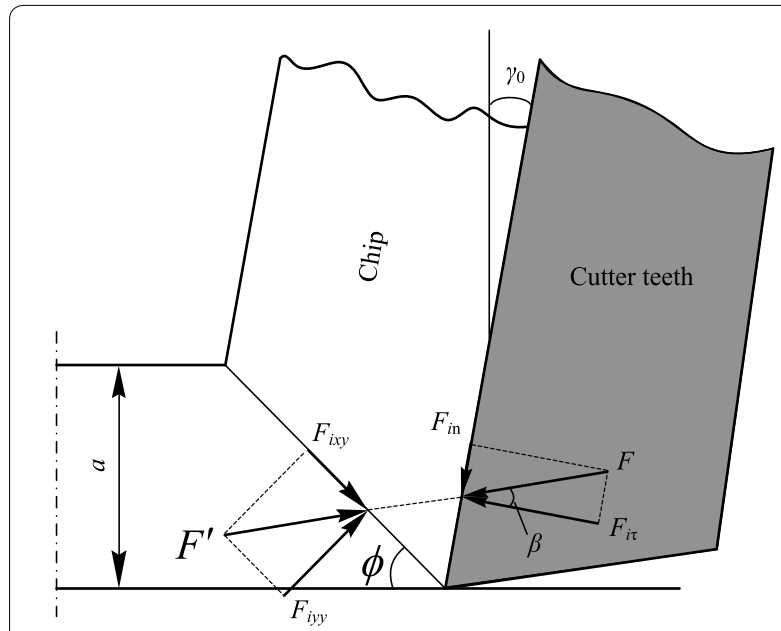

Figure 5 Resolution of cutting force where $\beta$ is the frictional angle between rake face and sands.

From Figure 4 the cutting force on the $i$ th cutter tooth in machine coordinate system is given by

$$
\left[\begin{array}{c}
F_{i X} \\
F_{i Y}
\end{array}\right]=\left[\begin{array}{cc}
\cos \left(\varphi_{i}-\gamma_{0}\right) & \sin \left(\varphi_{i}-\gamma_{0}\right) \\
\sin \left(\varphi_{i}-\gamma_{0}\right) & -\cos \left(\varphi_{i}-\gamma_{0}\right)
\end{array}\right]\left[\begin{array}{c}
F_{i \tau} \\
F_{i \mathrm{n}}
\end{array}\right] .
$$

When $N$ cutter tooth simultaneously cut the sand mould, the cutting force is the superposition of the $N$ cutting forces:

$$
\left(F_{X}, F_{Y}\right)^{\mathrm{T}}=\sum_{i}^{N}\left(F_{i X}, F_{i Y}\right)^{\mathrm{T}} .
$$

The calculation process of cutting force of milling sand mould is summarized in Figure 6.

\section{Experimental Verification}

To validate the model, the machining experiment of dynamic cutting force was carried out by up milling the coated sand with mesh granularity of 70/140. Table 1 lists the sand's physical parameters, while Table 2 lists the tool's parameters.

The machining experiments were performed in the sand mould machining center CAMTC-SMM1000, and the cutting force was measured using a three-axes piezoelectric dynamometer YDX-III9702 in which

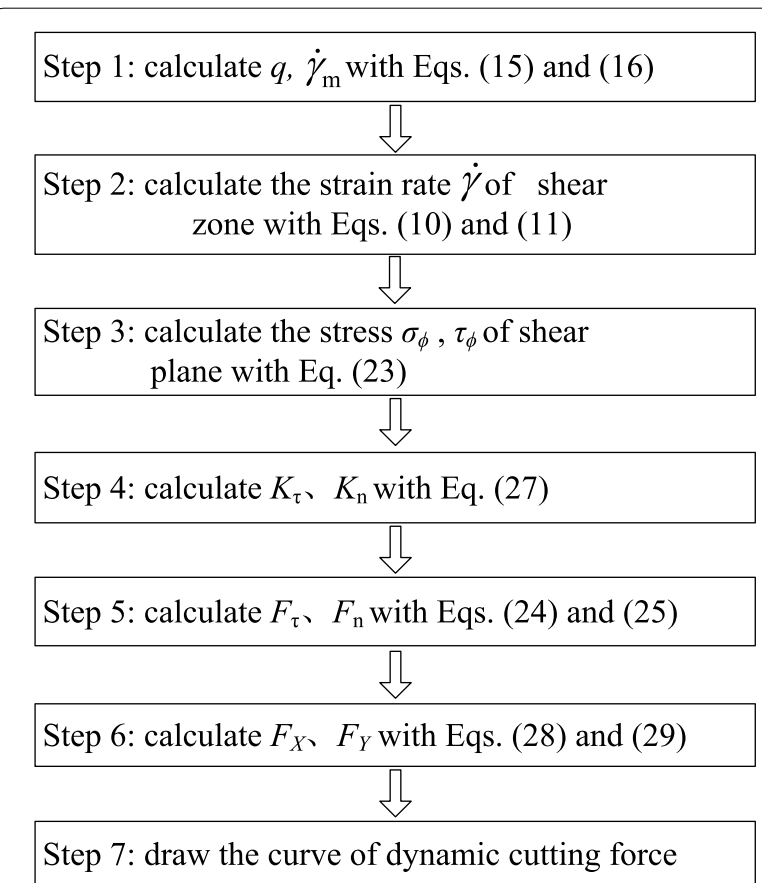

Figure 6 Calculation process of milling sand mould 
Table 1 Sand mould physical parameters

\begin{tabular}{ll}
\hline Parameter & Value \\
\hline Critical volume fraction $C_{\mathrm{vr}}$ & 0.64 \\
Static internal friction angle $\phi_{0}\left(^{\circ}\right)$ & 26.33 \\
Density $\rho_{\mathrm{p}}\left(\mathrm{kg} / \mathrm{m}^{3}\right)$ & 2600 \\
Mean diameter $d(\mathrm{~mm})$ & 0.144 \\
Shear angle $\phi\left(^{\circ}\right)$ & 31.84 \\
Axial compression strength $\sigma_{\mathrm{s}}(\mathrm{MPa})$ & 16.5 \\
Frictional angle between rake face and sands $\beta\left(^{\circ}\right)$ & 10
\end{tabular}

Table 2 Tool parameters

\begin{tabular}{lc}
\hline Parameter & Value \\
\hline Rake angle $\gamma_{0}\left({ }^{\circ}\right)$ & 0 \\
Teeth number & 2 \\
Radius of cutter $R(\mathrm{~mm})$ & 8 \\
Helical angle $\left(^{\circ}\right)$ & 0 \\
Flank angle $a_{0}\left({ }^{\circ}\right)$ & 20 \\
\hline
\end{tabular}

the sampling frequency was set to $60 n$ ( $n$ is the spindle turning speed). The measurement system is shown in Figure 7. Four representative experiments were designed and their process parameters are given in Table 3.

In the machining experiments, the self-excited vibration was carefully avoided, since it has a strong compact on the cutting forces. In order to avoid that, the spindle turning frequency was acquired far away from the region of self-excited vibrations. In addition, the
Table 3 Milling parameters

\begin{tabular}{lllll}
\hline Milling condition & \multicolumn{4}{l}{ Test number } \\
\cline { 2 - 5 } & Test $\mathbf{A}$ & Test $\mathbf{B}$ & Test $\mathbf{C}$ & Test $\mathbf{D}$ \\
\hline$a_{\mathrm{p}}(\mathrm{mm})$ & 3 & 3 & 3 & 5 \\
$n(\mathrm{r} / \mathrm{min})$ & 6000 & 6000 & 9000 & 6000 \\
$v_{X}(\mathrm{~mm} / \mathrm{s})$ & 100 & 160 & 100 & 100 \\
$a_{\mathrm{e}}(\mathrm{mm})$ & 14.4 & 14.4 & 14.4 & 14.4 \\
\hline
\end{tabular}

measured signals of the cutting force were filtered by a software to remove noise influence.

\section{Results and Discussions}

Figure 8 shows the predicted and the measured dynamic cutting force in the sand mould milling corresponding to milling conditions in Table 3.

\subsection{Validation and Discrepancy Discussions}

Figure 8 shows that the fluctuation cycles of the predicted and measured dynamic cutting force are in good agreement, and only slight deviations in dynamic curve exist. The main reasons are the following.

\subsubsection{Effect of Cutting Edge Radius}

In the prediction model, the cutting edge is assumed absolutely sharp. Nevertheless, in the actual tool, the cutting edge is a circular arc transition with the radius of $r_{\mathrm{n}}$ between the rake face and the flank that increases with the tool wear. The radii of cutting edge and sand

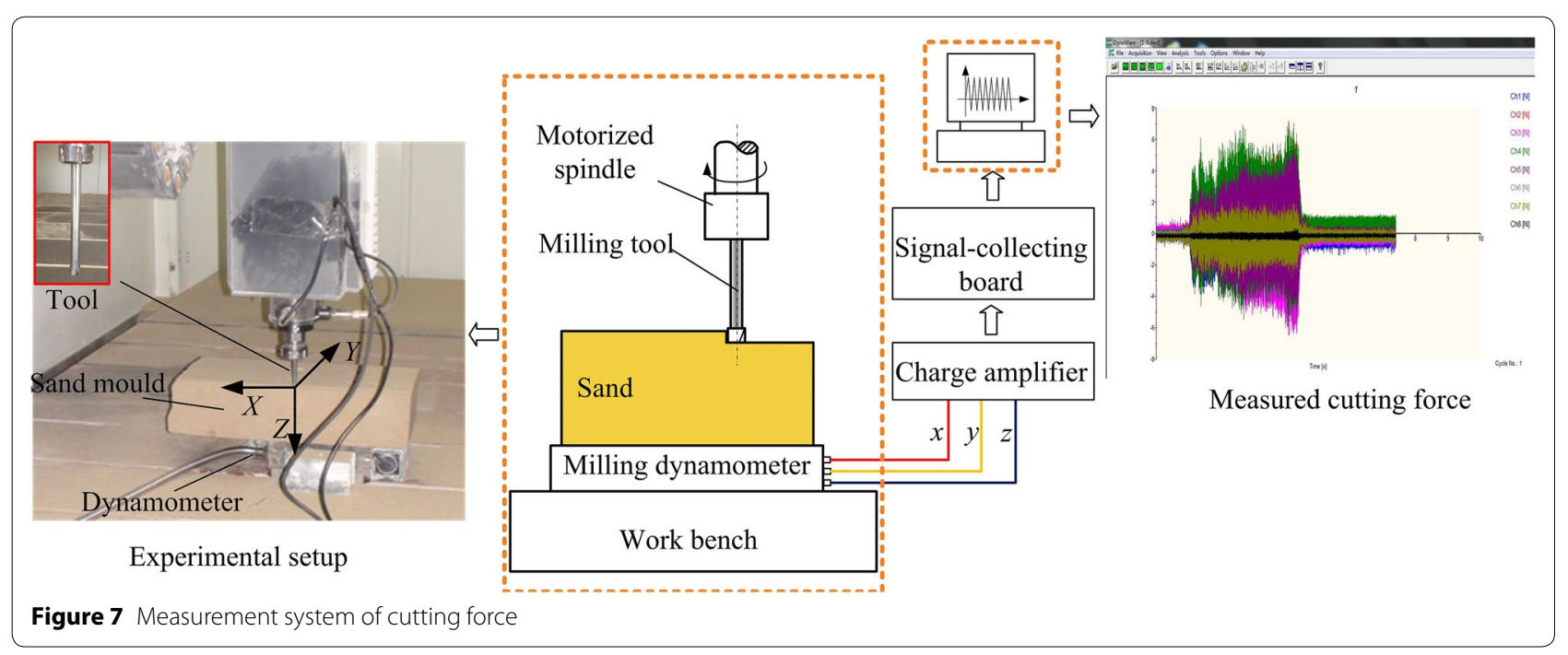




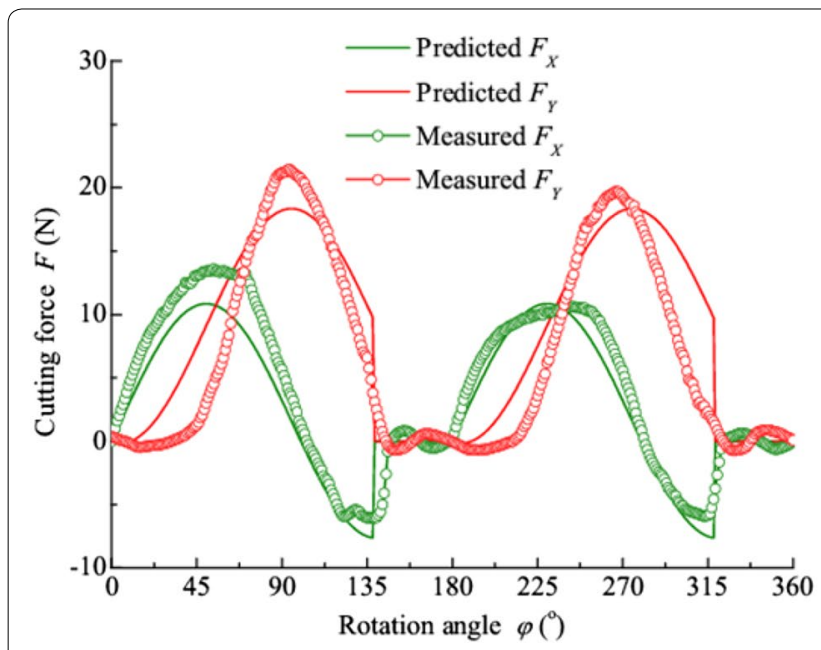

a Test $\mathrm{A}$

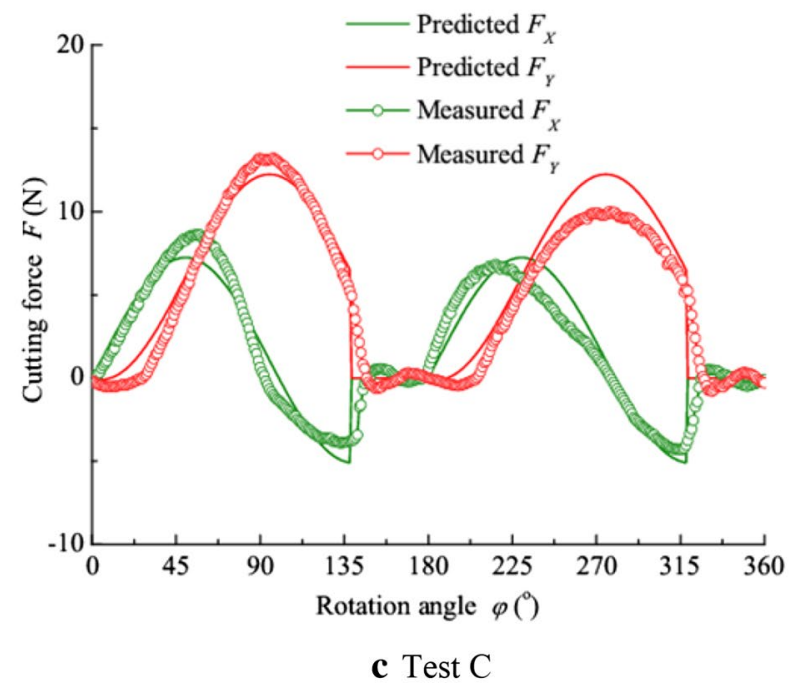

Figure 8 Predicted and measured cutting force

particle are of the same order. When cutting the sand mould, some sand particles at the bottom of the cutting layer are forced into the sand workpiece by the cutting edge without becoming a chip, which is similarly to the pure ploughing process of micro-cutting [25]. The mechanism is shown in Figure 9. The number of sand particles forced into the workpiece increases with the cutting edge radius. The interaction force $F_{1}$ between the sand particles and the cutting edge increases linearly with its radius as discussed in Refs. [26-28] as ploughing force. From Figure $9, F_{1}$ can be decomposed along the machine coordinate to

$$
\left\{\begin{array}{l}
F_{1 X}=F_{1} \sin \left(\varphi_{i}+\vartheta+\beta\right), \\
F_{1 Y}=-F_{1} \cos \left(\varphi_{i}+\vartheta+\beta\right),
\end{array}\right.
$$
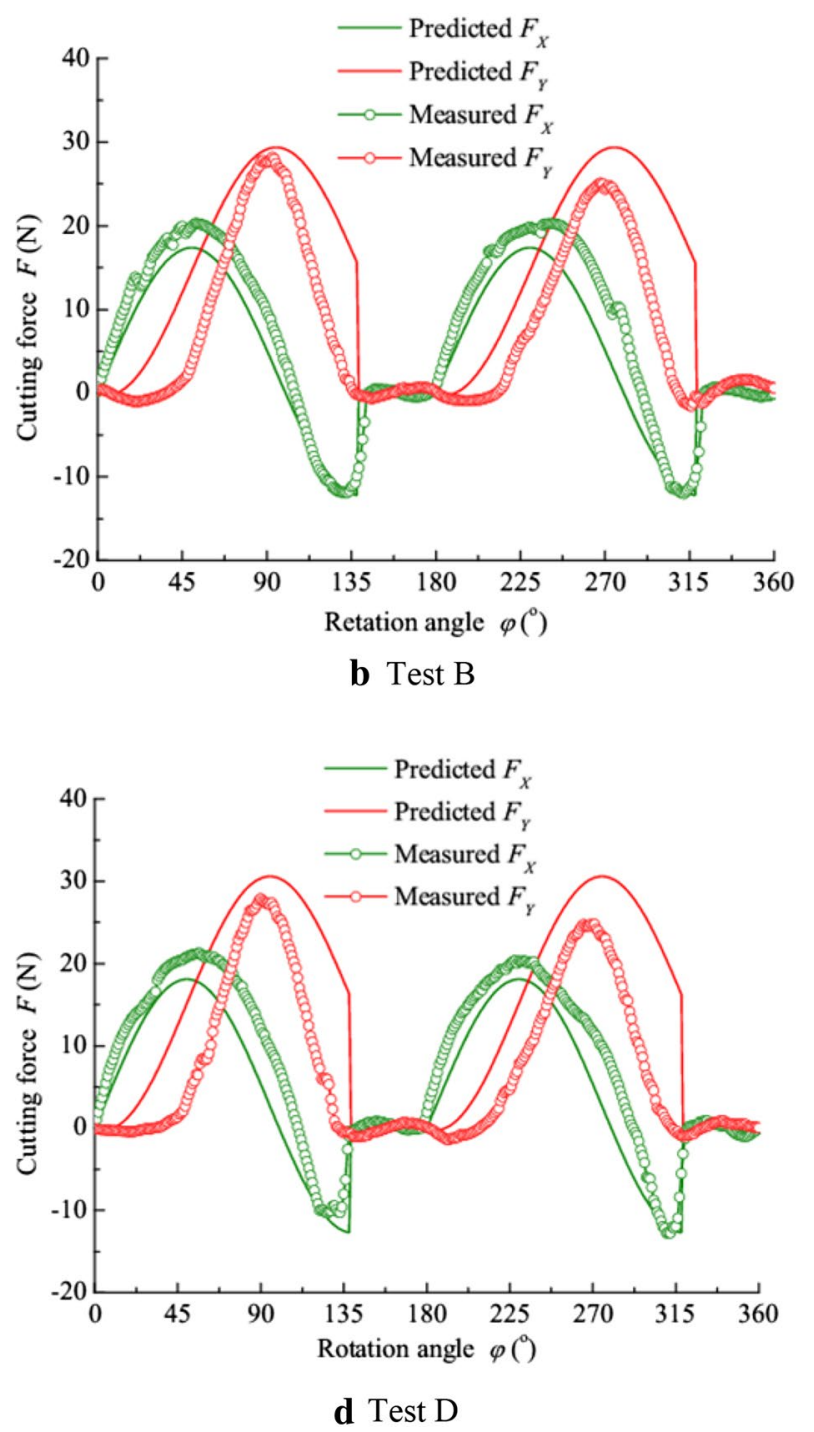

where $\vartheta$ is the interaction angle between sand particle and cutting edge, $\vartheta \in[0, \pi / 2]$. According to Eq. (30), the measured cutting forces in $X$-direction are greater than the predicted results and the measured cutting forces in $Y$-direction offset the predicted results slightly. Besides, $F_{1}$ also influences the amplitudes of cutting force. Figure 10 shows the comparison between the predicted and measured amplitudes of cutting forces. In the experiments, the cutting edge radius was detected as $r_{\mathrm{n}}=58.4 \mu \mathrm{m}$. The measured amplitudes of cutting forces in $X$-direction are larger than the predicted results by an average of $15 \%$. 


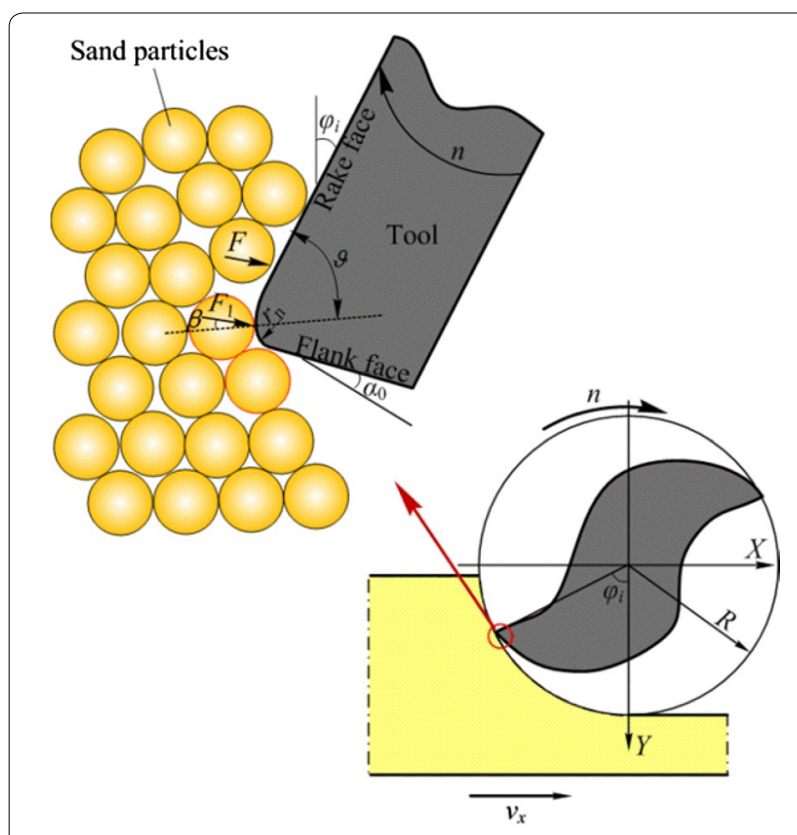

Figure 9 Force components with cutting edge effect

\subsubsection{Effect of Shear Zone Thickness}

During milling, the thickness of cutting layer varies with the rotation of cutter (Eq. (24)), and the thickness of the shear zone is also changed. In the prediction model, the thickness of shear zone is regarded as the average of the $3 D$, which causes the curves of predicted cutting force separate the measured curve slightly.

\subsubsection{Effect of the Non-uniform of Sand Mould}

According to the constitutive equation of sand mould shear zone (Eq. (23)), for the sand mould with uniform grain size, there are two aspects of the influence of particle size on cutting force. One is the static strength of sand mould, the other are the linear and quadric terms of shear rate which are the momentum and kinetic energy of the moving sand respectively. In general, the static strength of sand mould increases with the increase of the diameter of sand, and the momentum and kinetic energy of the single sand also increase with the diameter of sand particles. So the cutting force of the sand mould increases with the diameter increasing. However, the sand granularity in the sand mould is of $70 / 140$, which means that the size of sand distributes randomly within a certain range. Therefore, the distributions of the sand particles and strength are non-uniform. In the sand mould cutting process, when cutting the large sand particle or the region with higher strength, the cutting forces will increase. Otherwise, cutting forces will decrease. In the constitutive equations of prediction model (Eq. (23)), the compression strength $\sigma_{\mathrm{s}}$ is calculated as the macroscopical experimental results of the sand mould, and the sand particle diameter is calculated as an average diameter. That means the predictive model does not consider the effect of non-homogeneity, so the fluctuation of predicted cutting force is lower than the measured results.

\subsubsection{Effect of Elasticity of Sand Mould and Tool}

The prediction model considers both sand mould and tool as rigid body, so the predicted results ignore the force fluctuation caused by their elastic deformation. On the other hand, collisions and impacts between the tool and sand particles will intensify the fluctuation of cutting force as discussed in Ref. [29].

\subsection{Sand Mould Milling Process Analysis}

From the predicted and measured milling forces amplitudes shown in Figure 10, the main machining parameters that significantly influence the cutting force are the following:

1. The increasing of spindle feeding speed $v_{X}$ will lead to the higher thickness of cutting layer $a$ derived from Eq. (24). So, the increase of cutting forces is proportional to that of spindle feeding speed as shown in Figure 10(a).

2. According to Eq. (25), being other cutting conditions the same, the cutting forces are directly proportional to the increase of spindle feeding depth shown in Figure 10(b).

3. According to Eq. (24), the feeding per tooth $f$ is inversely proportional to the spindle turning speed $n$, thus the cutting forces decrease with the increase of spindle turning speed $n$. On the other hand, the cutting velocity $v$ increases with spindle turning speed $n$, which can in turn increase the shear strain rate $\dot{\gamma}$ of shear zone (Eq. (16)). According to the quasisolid-liquid transition constitutive equation of sand mould cutting (Eq. (23)), the stress in the shear zone will increase the cutting forces. Based on a comprehensive consideration of the above two factors, the cutting forces, therefore, decrease with the increase of spindle turning speed $n$ but disproportionately, as Figure 10(c) shows.

4. Milling feeding depth $a_{\mathrm{e}}$ mainly affects the interval of the cutter rotation angle $\varphi$. At small milling feeding, the rotation angle $\varphi$ of cutting the sand mould is so small that the milling forces do not reach the peaks and fall to zero. So, the milling forces are small as shown in Figure 10d $\left(a_{\mathrm{e}}=1.6 \mathrm{~mm}\right)$. When the milling feeding $a_{\mathrm{e}}$ is so large that the milling forces can reach 


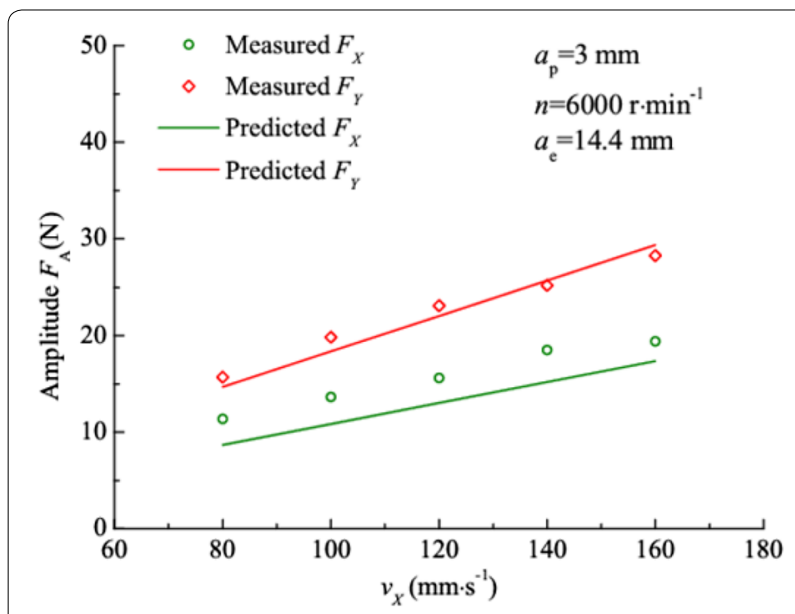

a Effect of spindle feeding speed

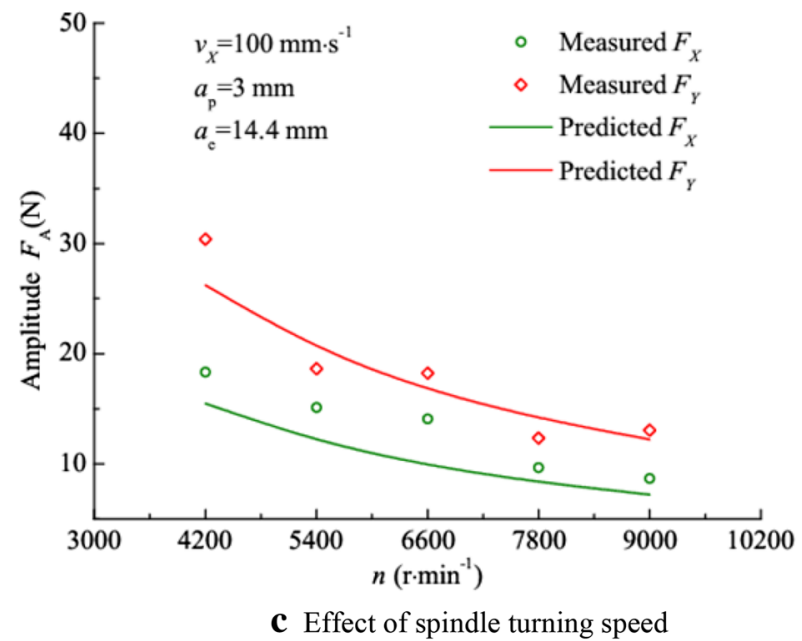

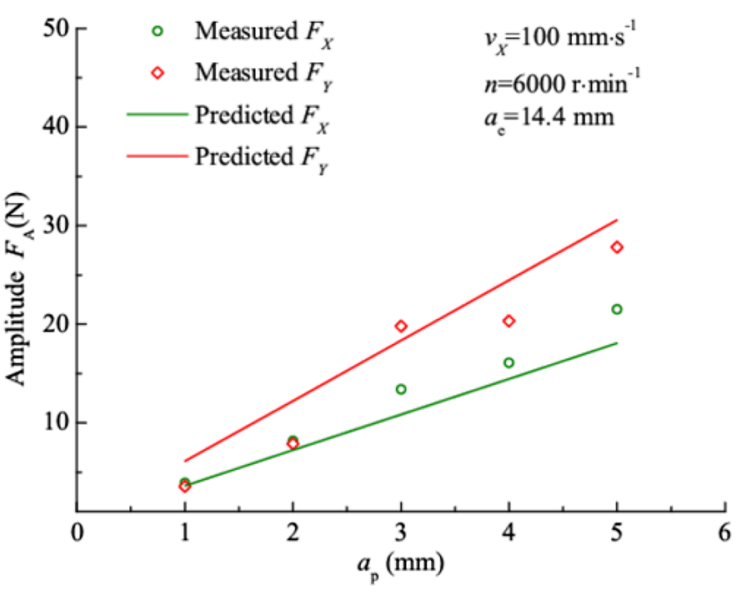

b Effect of spindle feeding depth

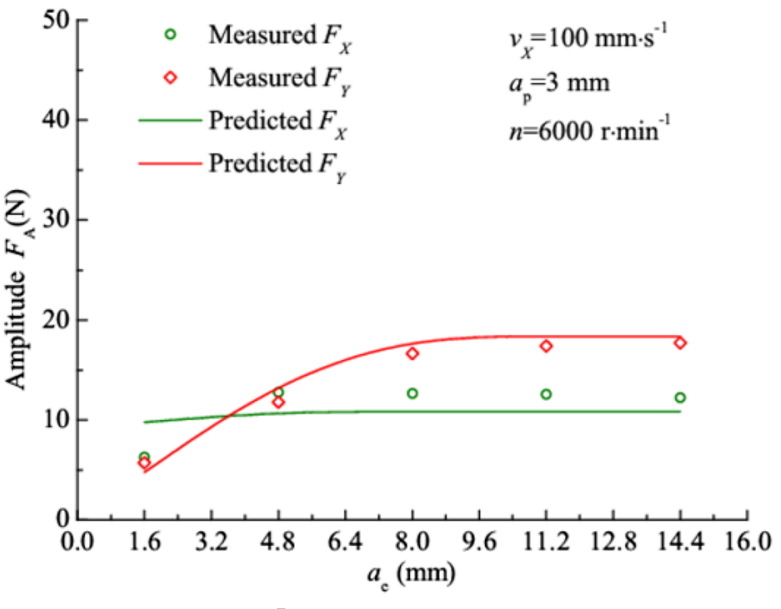

d Effect of milling feeding

Figure 10 Comparison between predicted and measured amplitude of cutting forces

the peak, the peak values will be the amplitudes. So, the amplitudes of milling forces become constant, as shown in Figure 10(d) $\left(a_{\mathrm{e}}>8 \mathrm{~mm}\right)$.

In the process of sand mould milling, the optimal process should be chosen considering both the machining efficiency and the cutting force, which can help to deal with the related problems such as tool wear and machining precision. In this respect, the prediction model proposed in this paper can provide an effective way to calculate the cutting force.

\section{Conclusions}

1. The analytical model of cutting force is established successfully for sand mould milling. In this model, the static strength and dynamic effect are considered. The predicted results are verified by machining test.
2. Based on the unequal division shear zone model, the wide zone and narrow zone in the shear zone of sand mould cutting are defined. There are two layers of sands in the wide zone and a layer of sands in the narrow zone.

3. The shear strain rate in the shear zone is proposed as power relation to the position of the sand particle. The flow stress on the shear plane is calculated by the shear strain rate and the constitutive equation of quasi-solid-liquid transition, thus the dynamic cutting forces of milling sand mould are predicted.

4. The amplitude of cutting force is proportional to the milling feeding depth and the spindle feeding speed, and reduce with the increasing of spindle turning speed, and is little influenced by milling feeding.

5. According to the prediction results of sand mould cutting force, the suitable processing parameters can be selected to achieve the effect of both efficiency 
and processing performance. The predicted cutting force can also be used to further study the tool wear and surface quality of the process in future work.

\section{Authors' Contributions}

Z-DS was in charge of the whole trial. F-XZ wrote the manuscript. Both authors read and approved the final manuscript.

\section{Author Details}

1 State Key Laboratory of Advanced Forming Technology and Equipment, China Academy of Machinery Science Technology, Beijing 100083, China.

2 Jiangsu University of Technology, Changzhou 213001, China.

\section{Authors' Information}

Zhong-De Shan, born in 1970, is currently a research professorship and PhD candidate supervisor at State Key Laboratory of Advanced Forming Technology and Equipment, China Academy of Machinery Science and Technology, China. His main research interests include advanced forming process and intelligent equipment.

Fu-Xian Zhu, born in 1979, is currently a PhD candidate at State Key Laboratory of Advanced Forming Technology and Equipment, China Academy of Machinery Science and Technology, China; and is an associate professor at Jiangsu University of Technology. His main research interests include digital forming technology and equipment.

\section{Acknowledgements}

The authors sincerely thanks to Professor Feng Liu of State Key Laboratory of Advanced Forming Technology and Equipment for his critical discussion and reading during manuscript preparation.

\section{Competing Interests}

The authors declare that they have no competing interests.

\section{Funding}

Supported by National Natural Science Foundation of China for Distinguished Young Scholars (Grant No. 51525503).

\section{Publisher's Note}

Springer Nature remains neutral with regard to jurisdictional claims in published maps and institutional affiliations.

Received: 13 April 2017 Accepted: 5 December 2018

Published online: 21 December 2018

\section{References}

[1] Z D Shan, SY Qin, Q Liu, et al. Key manufacturing technology \& equipment for energy saving and emissions reduction in mechanical equipment industry. International Journal of Precision Engineering and Manufacturing, 2012, 13(7): 1095-1100.

[2] X L Dong, XY Li, Z D Shan, et al. Rapid manufacturing of sand molds by direct milling. Tsinghua Science and Technology, 2009, 14(6): 212-215.

[3] C A Brown, B FV Turkovich. A practical method for estimating machining forces from tool-chip contact area. CIRP Annals - Manufacturing Technology, 1983, 32(1): 91-95.

[4] K Patra, A K Jhaa, T Szalay, et al. Artificial neural network based tool condition monitoring in micromechanical peck drilling using thrust force signals. Precision Engineering, 2017, 48: 279-291.

[5] P L B Oxley. Mechanics of machining: an analytical approach to assessing mach inability. Wes Sussex, England: Ellis Horwood; 1989.

[6] J Weng, KJ Zhuang, D Chen, et al. An analytical force prediction model for turning operation by round insert considering edge effect. International Journal of Mechanical Sciences, 2017: 128-129: 168-180.
[7] W Bai, R L Sun, A Roy, et al. Improved analytical prediction of chip formation in orthogonal cutting of titanium alloy Ti6Al4V. International Journal of Mechanical Sciences, 2017, 133: 357-367.

[8] F Jiang, T Zhang, L Yan. Analytical model of milling forces based on time-variant sculptured shear surface. International Journal of Mechanical Sciences, 2016, 115-116: 190-201.

[9] M E Merchant. Mechanics of the metal cutting process I. orthogonal cutting and a type 2 chip. Journal of Applied Physics, 1945, 16(5): 267-275.

[10] V P Astakhov, M O M Osman, M T Hayajneh. Re-evaluation of the basic mechanics of orthogonal metal cutting: velocity diagram, virtual work equation, and upper bound theorem. International Journal of Machine Tools \& Manufacture, 2001, 41: 393-418.

[11] J H Zhou, J X Ren, Y Z Feng, et al. A modified parallel-sided shear zone model for determining material constitutive law. International Journal of Advanced Manufacturing Technology, 2017, 91: 589-603.

[12] M Oda, K Iwashita. Study on couple stress and shear band development in granular media based on numerical simulation analyses. International Journal of Engineering Science, 2000, 38: 1713-1740.

[13] ZW Gao, J D Zhao. Strain localization and fabric evolution in sand. International Journal of Solids \& Structures, 2013, 50: 3634-3648.

[14] G Q Wang, G Xiong, HW Fang. General constitutive relations of granular flow. Science in China (Series E), 1998, 28(3): 282-288. (in Chinese)

[15] C S Campbell. Granular shear flows at the elastic limit. Journal of Fluid Mechanics, 2002, 465: 261-291.

[16] R Chand, SV Muniandy, C S Wong, et al. Discrete element method study of shear-driven granular segregation in a slowly rotating horizontal drum. Particuology, 2017, 32: 89-94.

[17] F Q Gao, D Stead, D Elmo. Numerical simulation of microstructure of brittle rock using a grain-breakable distinct element grain-based model. Computers \& Geotechnics, 2016, 78: 203-217.

[18] G Ma, W Zhou, X L Chang, et al. A hybrid approach for modeling of breakable granular materials using combined finite-discrete element method. Granular Matter, 2016, 18(1): 1-17.

[19] J Rojek. Discrete element thermomechanical modeling of rock cutting with valuation of tool wear. Computational Particle Mechanics, 2014, 1(1): 71-84.

[20] N Tounsi, J Vincenti, A Otho, et al. From the basic mechanics of orthogonal metal cutting toward the identification of the constitutive equation. International Journal of Machine Tools \& Manufacture, 2002, 42: 1373-1383.

[21] I Vardoulakis. Shear band inclination and shear modulus of sand in biaxial tests. International Journal for Numerical and Analytical Methods in Geomechanics, 1980, 4: 103-119.

[22] N Tounsi, JVincenti, A Otho, et al. From the basics of orthogonal metal cutting toward the identification of the constitutive equation. International Journal of Machine Tools \& Manufacture, 2002, 42(2): 1373-1383.

[23] D Z Zhang, R M Rauenzahn. Stress relaxation in dense and slow granular flows. Journal of Rheology, 2000, 44(5): 1019-1041.

[24] D M Hanes, D L Inman. Observations of rapidly flowing granular fluid flow. Journal of Fluid Mechanics, 1985, 150: 357-380.

[25] H S Yoon, K F Ehmann. Dynamics and stability of micro-cutting operations. International Journal of Mechanical Sciences, 2016, 115-116: 81-92.

[26] I H Ahn, S K Moon, J Hwang. A mechanistic cutting force model with consideration of the intrinsic and geometric size effects decoupled. International Journal of Advanced Manufacturing Technology, 2015, 81: $745-753$.

[27] L Zhou, FY Peng, R Yan, et al. Analytical modeling and experimental validation of micro end-milling cutting forces considering edge radius and material strengthening effects. International Journal of Machine Tools \&Manufacture, 2015, 97: 29-41.

[28] XWu, L Li, N He, et al. Influence of the cutting edge radius and the material grain size on the cutting force in micro cutting. Precision Engineering, 2016, 45: 359-364.

[29] H Z Li, W B Zhang, X P Li. Modeling of cutting forces in helical end milling using a predictive machining theory. International Journal of Mechanical Sciences, 2001, 43: 1711-1730. 